\title{
PRODUCTION OF TORTILLA CHIPS FROM CORN AND/OR SORGHUM: \\ V. STORAGE STABILITY WITH REGARD TO ANTIOXIDANTS USED
}

\author{
Shalaby, A. R.*; Nefisa A. Hegazy*; F. A. Salem*; Somaya M. Abd \\ El-Moneim ${ }^{\star *}$ and A. M. Hussein* \\ * Food Sci. and Tech. Dept., National Research Centre, Dokki, Cairo and \\ ${ }^{\star *}$ Food Sci. Dept., Fac. Agric., Zagazig Univ., Zagazig, Egypt.
}

\begin{abstract}
This work was carried out to investigate storage stability of tortilla chips with regard to antioxidants used during manufacturing. Tortilla chips were made from WC10 and YC/DS, fried in sun flower oil containing $0.015 \%$ of synthetic (BHT) or natural ( $\alpha$-tocopherol) antioxidants, packaged in M/PP and stored for three months at $28 \pm 77^{\circ} \mathrm{C}$ and $57 \pm 17 \%$ relative humidity. Chemical (acid value, peroxide value and TBA) and sensory attributes as well as crispiness were followed up during storage period. The obtained data revealed that both BHT and a-tocopherol can be successfully used for retarding both oxidative and hydrolytic rancidity of tortilla chips and hence prolong their shelf-life. The sensory evaluation clarified that adding antioxidants to frying oil led to improve all sensory properties of tested tortilla chips, specially, odor and taste. Antioxidants decreased the changes occurred in both oil and moisture contents and had a positive effect on the crispness of the stored tortilla chips.
\end{abstract}

\section{INTRODUCTION}

Corn considered as one of the principal crops in Egypt and its production is increasing annually. As well as, sorghum, which is considered the fifth most important cereal in total world production, used in Latin American countries because it is cheaper, produces higher grain yields, and has composition, properties and nutritional value similar to corn. Therefore, it would be beneficial to manufacture corn and sorghum as food stuffs and trying to introduce a new corn product to Egyptian food market.

In Mexico and Central America corn grains are considered the main source of bread substitution where these populations prepared many products from corn, i.e. snacks and convenience foods, such as tortillas, taco shells, tostads, tomales and tortilla chips. These products have rapidly spreaded in other countries and became main brands in food markets of these countries during the last decade. Several workers (Choto et al., 1985; Serna-Saldivar et al., 1988a) have demonstrated that acceptable tortillas can be made from sorghum and sorghum-maize mixtures in both laboratory and commercial productions. In Egypt, tortilla chips were made from corn and sorghum by the nixtamalization process and the physicochemical changes occurred in starch granules (Hegazy, et al., 2004) as well as the starch gelatinization and crystallinity were evaluated using Scaning Electron Microscopy (SEM) and X-ray diffractometer (Shalaby, et al., 2004). Moreover, 
Shalaby, A. R. et al.

a palatable tortilla chips flavored with different agents were described (Hegazy, et al., 2008).

Tortilla chips are prepared by baking followed by deep-oil frying. Therefore, the shelf life of such products is depended upon both types of packaging materials and antioxidants used. Packaging materials play a vital role in the maintenance of the shelf life of foods, however there is no general packaging solution and the type of packaging is individually stipulated for each product (Stöllman et al., 1992). Metallized plastic has been suggested as efficient light, oxygen and water vapor barriers for packaging of such products (Mohamed, 1997). In this concern, we found that polypropylene metallized with aluminum film (M/PP) was the best packaging materials for tortilla chips according to chemical and sensory evaluation (Shalaby et al., 2008), since it avoids light-induced rancidity and improves shelf life of crisps.

Concerning antioxidant agents, since oil is the most important ingredient used in manufacture of such products, they affect the keeping quality of tortilla chips and are the basic factor responsible for rancidity development during storage (Branen et al., 1990). The accepted means of delaying the onset of oxidative rancidity is the addition of antioxidants. Synthetic antioxidants such as butylated hydroxy toluene (BHT), butylated hydroxy anisole (BHA) and propyle gallate (PG) are widely used in many food products to prevent fat rancidity (Mahmoud, 1999). However, natural sources of antioxidant agents are preferred to face dietary and healthy problems resulting from the utilization of synthetic antioxidants. There are many natural occurring compounds, such as phytosterols, licithin, flavonoids, and tocopherols, existing in numerous plant materials and have antioxidants effects, which can be safety used in foods (Pokorny, 1991). Moreover, spices, herbs and essential oils have some antioxidant effects, and can be used as safely natural antioxidants in foods (Houliham and Ho, 1985). Anon (1991) described the health aspects of rice bran oil together with its properties in extending the shelf life of fried snacks such as potato, corn and tortilla chips. So, this study was conducted to evaluate several antioxidant agents for their effect on the stability of tortilla chips packaged in polypropylene metallized with aluminum film (M/PP) and stored under certain conditions

\section{MATERIALS AND METHODS}

\section{Materials:}

Grains:

White corn (Zea mays), single cross 10 (WC10) and local variety (Dorado) sorghum (DS) (Sorghum bicolor L.) were purchased from corn Breeding section, Field Crops Department, Agric. Res. Centre, Giza, Egypt. Chemicals:

DI- $\alpha$-Tocopherol as a natural antioxidant was purchased from Merck Company Trade, Germany, and butylated hydroxy toluene (BHT) as synthetic antioxidant (Purity 99.9\%) was obtained from Sigma U.S.A. Chemical Company. Calcium hydroxide was obtained from El-Gomhoriya Company Trade, Egypt. 


\section{Methods: \\ Technological methods}

Preparation of tortilla chips: Two kinds of tortilla chips were prepared from white corn and white corn/dorado sorghum in the Food Technology and Dairy Department, National Research Centre, Dokki Cairo, Egypt as mentioned previously (Serna-Saldivar et. al., 1988). The tortillas were then deep fried for $1 \mathrm{~min}$ at $190^{\circ} \mathrm{C}$ in sunflower oil containing a concentration of $0.015 \% \mathrm{BHT}$ or $\alpha$-Tocopherol. Tortilla chips were drained, cooled for $5 \mathrm{~min}$ and packaged in M/PP (the suitable packaging materials, Shalaby et al., 2008) and stored at temperature of $28+7 \circ \mathrm{C}$ and $\mathrm{RH}$ of $57 \pm 17 \%$ for three months. Samples were drawn at 15 days intervals for evaluation.

Analytical methods

Oil was extracted from tortilla chips following the method of Habib and Brown (1956). The stability tests of fresh oil and oil extracted from tortilla chips during 3 months of storage were measured by determination of the following parameters.

Acid value (A.V.) and peroxide value (P.V.) were determined according to the methods described in the A.O.C.S. (1964). Thiobarbituric acid (T.B.A) test was carried out according to the method described by Ottolenghi (1959).

Statistical analysis:

Results of sensory evaluation of tortilla chips were statistically analyzed using analysis of variance and least significant differences (L.S.D) according to the method of Gomez and Gomez (1984).

\section{RESULTS AND DISCUSSION}

Fried foods have a long shelf-life because of their low moisture content. However, oil oxidation or oxidative rancidity limits shelf-life. The main factors affecting deterioration of fatty foods include the degree of un-saturation, the conditions of storage, packaging materials and utilization of antioxidants. Regardless packaging materials, antioxidants effectively prolong the shelf-life of fried products stored under room conditions. So in this concern different kinds of antioxidants were evaluated for their effect on stability of tortilla chips stored under certain conditions.

The least stable macro-components in food are the lipids. The food becomes unacceptable and rejected by the consumer as a result of rancidity development. To enhance the shelf-life of such foods and prevent the occurrence of rancidity the presence of antioxidants is required. These antioxidants may be added to the food product during processing. In this concern, the effect of antioxidants on stability of tortilla chips during storage was followed. Both synthetic (BHT) and natural ( $\alpha$-tocopherol) antioxidants were individually added to the deep frying oil, i.e. sunflower oil, with concentration of $0.015 \% \mathrm{BHT}$ or $\alpha$-Tocopherol and the fried chips were packaged in M/PP film and stored for three months. The storage stability of tortilla chips was evaluated according to the chemical and sensory attributes. 


\section{Chemical quality attributes:}

The changes in fat quality parameters i.e. AV, PV and TBA, of $M / p p$ packed tortilla chips prepared with either synthetic as natural antioxidants (BHT or a-tocopherol) were followed throughout storage period for 90 days, and the obtained results are given in Table (1). It could be noticed that the AV increased gradually up to the end of storage time in both samples. The AV of WC10 tortilla chips increased from $1.58 \mathrm{mg} \mathrm{KOH} / 1 \mathrm{gm}$ oil to 3.34 and $3.00 \mathrm{mg}$ $\mathrm{KOH} / 1 \mathrm{gm}$ oil at end of the storage period when $\mathrm{BHT}$ and $\alpha$-tocopherol were used, respectively. The corresponding AV of YC/DS tortilla chips at the end of storage period were 3.65 and $2.66 \mathrm{mg} \mathrm{KOH} / 1 \mathrm{gm}$ oil. The obtained results revealed that the tortilla chip prepared with a-tocopherol had lower AV than those prepared with BHT.

Table (1): Effect of antioxidants on chemical quality attributes of tortilla chips packaged in M/PP during storage.

\begin{tabular}{|c|c|c|c|c|c|c|}
\hline \multirow{2}{*}{\begin{tabular}{|l} 
Storage \\
period (days)
\end{tabular}} & \multicolumn{3}{|c|}{ BHT } & \multicolumn{3}{|c|}{$\alpha$-tocopherol } \\
\hline & AV & PV & TBA & AV & PV & TBA \\
\hline \multicolumn{7}{|c|}{ WC10 tortilla chips } \\
\hline 0 & 1.60 & 4.32 & 0.096 & 1.58 & 4.40 & 0.094 \\
\hline 15 & 1.62 & 7.11 & 0.097 & 1.60 & 6.40 & 0.111 \\
\hline 30 & 1.58 & 9.72 & 0.097 & 1.63 & 9.58 & 0.113 \\
\hline 45 & 1.62 & 16.79 & 0.110 & 1.96 & 10.18 & 0.116 \\
\hline 60 & 1.98 & 33.61 & 0.115 & 2.05 & 16.61 & 0.117 \\
\hline 75 & 2.05 & 35.61 & 0.118 & 2.15 & 35.16 & 0.120 \\
\hline 90 & 3.34 & 60.43 & 0.123 & 3.00 & 70.03 & 0.124 \\
\hline \multicolumn{7}{|c|}{ YC/DS tortilla chips } \\
\hline 0 & 1.65 & 4.43 & 0.075 & 1.60 & 4.42 & 0.073 \\
\hline 15 & 1.75 & 7.03 & 0.085 & 1.62 & 6.30 & 0.088 \\
\hline 30 & 2.00 & 8.77 & 0.092 & 1.67 & 9.55 & 0.097 \\
\hline 45 & 2.13 & 15.76 & 0.113 & 2.15 & 9.18 & 0.110 \\
\hline 60 & 2.25 & 33.16 & 0.115 & 2.24 & 17.16 & 0.114 \\
\hline 75 & 2.68 & 42.03 & 0.120 & 2.50 & 40.30 & 0.118 \\
\hline 90 & 2.68 & 65.42 & 0.121 & 2.66 & 80.16 & 0.121 \\
\hline
\end{tabular}

Where: $\mathrm{AV}=$ acid value (mg KOH = FFA $/ 1 \mathrm{gm}$ oil)

PV = peroxide value (mequ. Peroxide $/ 1 \mathrm{~kg}$ oil)

TBA = thiobarbutric acid (mg malonaldehyd / $1 \mathrm{~kg}$ oil)

In general, addition of antioxidant to frying oil had good effect on decreasing the acidity of tortilla chips during storage, so prevents the undesirable changes in the taste and flavor. Similar findings were reported by Hallabo et al. (1986); Lean and Mohamed (1999) and Mahmoud (1999).

From the same Table (1), it could be noticed that the PV increased during storage period by different rates in the samples depending on the type of antioxidant used. The PV of WC tortilla chips prepared with BHT or atocopherol increased from 4.32 (at 0 -time) to 60.43 and 70.03 mequ. peroxide / $\mathrm{kg}$ oil, respectively (at the end of storage period). The corresponding values of YC / DS tortilla chips increased from 4.43 to 65.42 and 80.16. These results indicated that using antioxidants whether synthetic $(\mathrm{BHT})$ or natural ( $\alpha$-tocopherol) during frying the tortilla chips led to decrease the rate of peroxide formation in the samples during storage. These results 
are in agreement with those obtained by Hallabo et al. (1992); Hassanen (1998) and Mahmoud (1999).

Table (1) revealed also that TBA number increased by prolongation of the storage period in both treated samples. The TBA values of WC tortilla chips increased from 0.096 to 0.123 and $0.124 \mathrm{mg} \mathrm{Mal} . / \mathrm{kg}$ oil at the end of storage period in either $\mathrm{BHT}$ or a-tocopherol respectively. The corresponding values of YC / DS tortilla chips increased from 0.075 to 0.121 and $0.121 \mathrm{mg}$. These results are confirmed with those obtained by Mahmoud (1999) and ELSharkawy et al. (1999).

From the results regarding the chemical quality attributes (AV, PV and TBA) it could be concluded that the BHT and $\alpha$-tocopherol can be successfully used for retarding both oxidative and hydrolytic rancidity of tortilla chips and hence prolong their shelf-life.

\section{Sensory characteristics:}

Shelf-life of foods is a measure of how long food products maintain an optimal quality. Food quality decreases with time of storage where the undesirable quality changes may affect texture, odor, taste, color and overall acceptability. However, the rate and magnitude of many of these quality changes can be minimized with suitable antioxidants. Therefore, both WC and YC /DS tortilla chips were evaluated for their sensory quality. The obtained data were recorded in Table (2) along with the statistical analysis. It could be noted that BHT prolonged the shelf-life of the WC chips to 30 days, whereas $\alpha$-tocopherol prolonged it to 45 days as determined by color evaluation, where at these times no significant differences $(P<0.05)$ could be observed between the fresh product and the stored one. On the contrary, the color evaluation of YC/DS chips indicated that its shelf-life was extended to 45 days when BHT was used compared to 30 days as a result of using $\alpha-$ tocopherol as antioxidant. These results indicate that the effect of the antioxidants on the product shelf-life is differed according to the product kind. However, the property to be evaluated had a pronounced effect in the shelflife of the product. In this concern, it could be observed that where the shelflife of WC chips was 45 days when a-tocopherol is used as evaluated according to color, it was only 15 days as determined according to odor evaluation.

\section{Chemical characteristics:}

The oil content of different tortilla chips prepared with BHT or $\alpha$ tocopherol was determined after 15 days intervals of storage for 90 days at ambient temperature, and the obtained results are shown in Table (3). It could be noted that the oil content in all samples decreased during storage of packaged tortilla chips after 90 days. The observed decrease in the oil content of tortilla chips during storage could be mainly deferred to the adsorption of some oil which accumulated on the internal surface of the packaging film which has a resistance of grease. Addition of antioxidant BHT as $\alpha$-tocopherol to oil during frying led to a slight decrease in oil content during storage for 90 days comparing with the control. Such adsorption disruption of oil was affected by the type of packaging material used, storage condition especially temperature, storage time and addition of antioxidants. 
Shalaby, A. R. et al.

Table (2): Sensory evaluation of different tortilla chips containing BHT or $\alpha$-tocopherol and packed in M/PP during storage.

\begin{tabular}{|c|c|c|c|c|c|c|c|c|c|c|}
\hline \multirow{2}{*}{$\begin{array}{l}\text { Storage } \\
\text { (days) }\end{array}$} & \multicolumn{2}{|c|}{ Color (20) } & \multicolumn{2}{|c|}{ Odor (20) } & \multicolumn{2}{|c|}{ Taste (20) } & \multicolumn{2}{|c|}{ Texture (20) } & \multicolumn{2}{|c|}{ Appearance (20) } \\
\hline & BHT & pcophero & BHT & bcophero & BHT & bcopherc & $\mathrm{BHT}$ & bcophe & BHT & bcophero \\
\hline \multicolumn{11}{|c|}{ WC 10 tortilla chips } \\
\hline 0 & $18.4^{\mathrm{ABC}}$ & $18.4^{\mathrm{ABC}}$ & $18.5^{\mathrm{AB}}$ & $18.5^{\mathrm{AB}}$ & $18.9^{\mathrm{A}}$ & $18.9^{\mathrm{A}}$ & $19.0^{A B}$ & $19.0^{A B}$ & $18.8^{\mathrm{A}}$ & $18.8^{\mathrm{A}}$ \\
\hline 15 & $18.4^{\mathrm{ABC}}$ & $18.2^{\mathrm{A}-\mathrm{E}}$ & $18.4^{\mathrm{ABC}}$ & $18.2^{\mathrm{ABC}}$ & $18.0^{\mathrm{BC}}$ & $17.9^{\mathrm{C}}$ & $18.8^{\mathrm{ABC}}$ & $18.7^{A-E}$ & $18.0^{B-F}$ & $18.4^{A-D}$ \\
\hline 30 & $18.1^{\mathrm{A}-\mathrm{F}}$ & $18.0^{A-F}$ & $17.8^{\mathrm{BCD}}$ & $17.7^{\mathrm{CD}}$ & $17.6^{\mathrm{CD}}$ & $17.8^{\mathrm{CD}}$ & $18.1^{\mathrm{C}-\mathrm{F}}$ & $18.3^{\mathrm{B}-\mathrm{F}}$ & $17.9^{B-F}$ & $18.3^{A-F}$ \\
\hline 45 & $17.4^{\mathrm{C}-\mathrm{G}}$ & $17.6^{A-G}$ & $17.7^{\mathrm{CD}}$ & $17.7^{\mathrm{CD}}$ & $17.5^{\mathrm{CD}}$ & $17.6^{\mathrm{CD}}$ & $18.0^{\text {DEF }}$ & $18.2^{\mathrm{C}-\mathrm{F}}$ & $17.8^{\mathrm{C}-\mathrm{F}}$ & $18.0^{\mathrm{B}-\mathrm{F}}$ \\
\hline 60 & $17.3^{\mathrm{D}-\mathrm{G}}$ & $17.3^{\mathrm{D}-\mathrm{G}}$ & $17.5^{\mathrm{D}}$ & $17.6^{\mathrm{CD}}$ & $17.5^{\mathrm{CD}}$ & $17.4^{\mathrm{CD}}$ & $18.0^{\mathrm{DEF}}$ & $17.9^{\mathrm{C}-\mathrm{F}}$ & $17.8^{\mathrm{C}-\mathrm{F}}$ & $17.9^{B-F}$ \\
\hline 75 & $17.3^{\mathrm{D}-\mathrm{G}}$ & $17.1^{\mathrm{F}-\mathrm{G}}$ & $17.5^{\mathrm{D}}$ & $17.6^{\mathrm{CD}}$ & $17.3^{\mathrm{CD}}$ & $17.4^{\mathrm{CD}}$ & $17.9^{\mathrm{EF}}$ & $17.8^{\mathrm{F}}$ & $17.6^{\mathrm{EF}}$ & $17.7^{\mathrm{DEF}}$ \\
\hline 90 & $17.2^{\mathrm{EFG}}$ & $16.6^{G}$ & $17.5^{\mathrm{D}}$ & $17.5^{\mathrm{D}}$ & $17.0^{\mathrm{D}}$ & $17.3^{\mathrm{CD}}$ & $17.8^{\mathrm{F}}$ & $17.7^{\mathrm{F}}$ & $17.4^{\mathrm{F}}$ & $17.6^{\mathrm{EF}}$ \\
\hline \multicolumn{11}{|c|}{ YC/DS Tortilla chips } \\
\hline 0 & $18.5^{\mathrm{AB}}$ & $18.5^{\mathrm{AB}}$ & $18.8^{\mathrm{A}}$ & $18.8^{\mathrm{A}}$ & $18.8^{\mathrm{A}}$ & $18.8^{\mathrm{A}}$ & $19.3^{A}$ & $19.3^{A}$ & $18.6^{\mathrm{AB}}$ & $18.6^{\mathrm{AB}}$ \\
\hline 15 & $18.1^{\mathrm{A}-\mathrm{F}}$ & $18.3^{A-D}$ & $18.6^{A}$ & $18.7^{\mathrm{A}}$ & $17.9^{\mathrm{C}}$ & $17.9^{\mathrm{C}}$ & $18.7^{\mathrm{A}-\mathrm{E}}$ & $18.9^{\mathrm{ABC}}$ & $18.0^{B-F}$ & $18.3^{\mathrm{A}-\mathrm{E}}$ \\
\hline 30 & $17.8^{A-F}$ & $17.9^{A-F}$ & $17.7^{\mathrm{CD}}$ & $17.8^{\mathrm{BCD}}$ & $17.8^{\mathrm{CD}}$ & $17.7^{\mathrm{CD}}$ & $18.2^{\mathrm{C}-\mathrm{F}}$ & $18.4^{\mathrm{B}-\mathrm{F}}$ & $17.9^{B-F}$ & $18.0^{\mathrm{B}-\mathrm{F}}$ \\
\hline 45 & $17.6^{A-G}$ & $17.7^{\mathrm{D}-\mathrm{F}}$ & $17.6^{\mathrm{D}}$ & $17.7^{\mathrm{CD}}$ & $17.5^{\mathrm{CD}}$ & $17.6^{\mathrm{CD}}$ & $18.1^{\mathrm{C}-\mathrm{F}}$ & $18.1^{\mathrm{C}-\mathrm{F}}$ & $17.9^{\mathrm{B}-\mathrm{F}}$ & $17.9^{\mathrm{B}-\mathrm{F}}$ \\
\hline 60 & $17.5^{\mathrm{C}-\mathrm{G}}$ & $17.5^{B-G}$ & $17.5^{\mathrm{D}}$ & $17.6^{\mathrm{D}}$ & $17.4^{\mathrm{CD}}$ & $17.5^{\mathrm{CD}}$ & $18.1^{C-F}$ & $18.1^{\mathrm{C}-\mathrm{F}}$ & $17.8^{\mathrm{C}-\mathrm{F}}$ & $17.8^{C-F}$ \\
\hline 75 & $17.3^{\mathrm{D}-\mathrm{G}}$ & $17.4^{C-G}$ & $17.4^{\mathrm{D}}$ & $17.6^{\mathrm{D}}$ & $17.3^{\mathrm{CD}}$ & $17.4^{\mathrm{CD}}$ & $18.0^{\mathrm{DEF}}$ & $18.1^{\mathrm{C}-\mathrm{F}}$ & $17.8^{\mathrm{C}-\mathrm{F}}$ & $17.7^{\text {DEF }}$ \\
\hline 90 & $17.3^{D-G}$ & $17.3^{\mathrm{D}-\mathrm{G}}$ & $17.4^{\mathrm{D}}$ & $17.5^{\mathrm{D}}$ & $17.2^{\mathrm{CD}}$ & $17.0^{\mathrm{D}}$ & $18.0^{\mathrm{DEF}}$ & $17.9 \mathrm{EF}$ & $17.5^{\mathrm{F}}$ & $17.6^{\mathrm{EF}}$ \\
\hline \begin{tabular}{|l|} 
LSD at \\
$0.05 \%$
\end{tabular} & & \multicolumn{2}{|c|}{0.6585} & \multicolumn{2}{|c|}{0.7166} & \multicolumn{2}{|c|}{0.6620} & \multicolumn{2}{|c|}{0.6121} \\
\hline
\end{tabular}

The moisture contents of different tortilla chips prepared with added of $\mathrm{BHT}$ or $\alpha$-tocoherol were periodically determined fortnightly. Results obtained (Table, 3) indicate that the moisture content in all tortilla chips ranged between $1.47-1.50 \%$ after frying. Moreover, moisture content of all tortilla chips considerably increased during storage which can be ascribed to the moisture uptake of from the surroundings through the packaging materials. Also, it could be noticed that tortilla chips with a-tocopherol had lower moisture content than those treated with BHT. These results are in accordance with those reported by Abd El-Azim (1985) and Mahmoud (1999).

Table (3): Effect of moisture and oil contents (\%) on the tortilla chips crispiness packaged in M/PP and adding antioxidants during storage.

\begin{tabular}{|c|c|c|c|c|c|c|}
\hline \multirow{2}{*}{$\begin{array}{l}\text { Storage } \\
\text { days) }\end{array}$} & \multicolumn{3}{|c|}{ BHT } & \multicolumn{3}{|c|}{$\alpha$-tocopherol } \\
\hline & Moisture & Oil & crispiness & Moisture & Oil & crispiness \\
\hline \multicolumn{7}{|c|}{ WC10 tortilla chips } \\
\hline 0 & 1.50 & 28.79 & 0.025 & 1.47 & 28.85 & 0.05 \\
\hline 15 & 1.06 & 28.61 & 0.037 & 1.01 & 28.60 & 0.035 \\
\hline 30 & 1.21 & 28.77 & 0.042 & 1.23 & 28.74 & 0.043 \\
\hline 45 & 1.87 & 28.77 & 0.065 & 1.70 & 28.70 & 0.059 \\
\hline 60 & 1.32 & 28.36 & 0.047 & 1.32 & 28.30 & 0.047 \\
\hline 75 & 1.40 & 26.13 & 0.054 & 1.38 & 26.18 & 0.053 \\
\hline 90 & 1.37 & 27.95 & 0.049 & 1.59 & 27.81 & 0.057 \\
\hline \multicolumn{7}{|c|}{ YC/DS tortilla chips } \\
\hline 0 & 1.65 & 31.65 & 0.052 & 1.60 & 31.55 & 0.050 \\
\hline 15 & 1.20 & 31.60 & 0.038 & 1.15 & 31.00 & 0.037 \\
\hline 30 & 1.31 & 31.65 & 0.041 & 1.33 & 29.00 & 0.046 \\
\hline 45 & 1.90 & 31.60 & 0.060 & 1.56 & 28.66 & 0.054 \\
\hline 60 & 1.80 & 31.00 & 0.058 & 1.32 & 28.30 & 0.047 \\
\hline 75 & 1.61 & 29.54 & 0.055 & 1.43 & 29.17 & 0.049 \\
\hline 90 & 1.72 & 29.01 & 0.059 & 1.70 & 30.16 & 0.056 \\
\hline
\end{tabular}

11162 
The crispiness of tortilla chips is based on their moisture and oil content, when the ratio between these two parameters increased the crispness decreased (Gould, 1985). From the same table (Table, 3), it could be noted that the crispiness of tortilla chips slightly decreased throughout the storage period. Addition of either BHT or a-tocopherol to oil during frying led to slight change in oil and moisture content of stored tortilla chips. Of course this affected their crispness tortilla chips packaged in M/PP and added antioxidants had a higher crispness than the control. $\alpha$-tocopherol considered the best antioxidants that can be safety used for stored tortilla chips.

\section{REFERENCES}

Abd-El-Azim, N.A.F.A. (1985). Effect of added antioxidants on the quality characteristics of biscuits. M. Sci. Thesis, Fac. Agric., Cairo Univ., Egypt.

Anon. (1991) . Rice bran oil extends shelf life of snacks. Food- Engineering, $63(10): 30$.

A.O.C.S. (1964) . Official and Tentative Methods of the American Oil Chemists Society . Published by the American Oil Chemistry Society. 35, East Wacker Drive, Chicago, Illinois.

Branen,A.L.; P.M. Davidson and S. Salminen (1990). (Food Additives) Chapt. 5, pp.139- 191,Published by Marcel Dekker,INC. New York and Basel.

Choto, C.E.; M.M. Morad and L.W. Rooney (1985). The quality of tortillas containing whole sorghum and pearled sorghum alone and blended with yellow maize. Cereal Chem., 62: 51.

El-Sharkawy, A.A., H.K. Sohair and A.Y. Girgis (1999). Improving the quality of sunflower seed oil as frying oil . Egypt, J.Appl. Sci., 14 (1): 77 - 90

Gomez, K.A. and A.A. Gomez (1984). Statistical procedures for Agricultural Research. 2ed Chap. 3, pp. 84-129. John Wily and Sons Editors Fnc, USA.

Gould, W.A. (1985). Snack Food Quality Evaluation. Chipper/Snacker, 42 (7): 32.

Habib, A.T. and H.D. Brown (1956). Factors influencing the color of potato chips. Food Technology, March 12, 332 - 336.

Hallabo, S.A.; M.K. Mostafa and N.A. Nefery (1986) . Biscuits quality as affected by antioxidants, storage temperature and storage periods. Bull. Fac. of Agric., Univ. of Cairo, 37 (2): 733.

Hallabo, S.A.S., A.Z.A. Badei and E.M. Mohamed (1992) . Efficiency of some essential oils as natural occurring antioxidants. Egypt, J. Food Sci., 20 (3): 427-440.

Hassanen, M.H. Naglaa (1998). Utilization of some spices and their volatile oils as flavoring and preservative agents in biscuit. M. Sc. Thesis, Fac. Agric., Cairo Univ., Egypt .

Hegazy, Nefisa A., A. R. Shalaby, F. A. Salem, Somaya M. Abd El-Moneim and A. M. Hussein (2004). Production of tortilla chips from corn and/or sorghum. I. Physicochemical changes occurred in starch granules. J. Agric. Sci. Mansoura Univ., 29 (12) 7101- 7109. 
Shalaby, A. R. et al.

Hegazy, Nefisa A., A. R. Shalaby, F. A. Salem, Somaya M. Abd El-Moneim and A. M. Hussein (2008). Production of tortilla chips from corn and/or sorghum. III. chemical and sensory evaluation. Egypt. J. Nutr. XXIII : 25 $-48$.

Houliham, C.M. and Ho, C.T.(1985). Natural antioxidants. In: Flavor Chem . of Fats and Oils, Min, D.B., Smouse, T.H. (Eds.), AOCS Monograph 15.

Lean, L.P. and S. Mohamed (1999). Antioxidative and antimycotic effects of turmeric, lemon-grass, betel leaves, clove, black pepper leaves and garcinia atrivirdis on butter cakes . J.Sci. Food Agric., 79: 1817-1822.

Mahmoud, B.S. (1999). Application of cardamom, cinnamon and clove spices and their volatile oils in preservation and flavoring of cookies. M.Sc. Thesis, Fac. Of Agric. Cairo Univ., Egypt.

Mohamed, S.A.Z. (1997). Effect of packaging materials on the shelf life of potato chips stored at different conditions. M.Sc. Thesis, Food Sci. and Tech., Fac. Agric, Cairo univ, Egypt.

Ottolenghi, A. (1959). Interaction of ascorbic acid and mitochondrial lipids. Arch. of Biochem. and Biophy., $79: 355-363$.

Pokorny, J. (1991). Natural antioxidants for food use. Trends Fd Sci. Technol. (September), 223-227.

Serna - Saldivar, S.O; A. Tellez - Giron and L.W. Rooney (1988). Production of tortilla chips from sorghum and maize . J. Cereal Sci., 8 (2) : 275 284 .

Serna-Saldivar, S.O.; L.W. Rooney and R. D. Waniska (1988a). Wheat flour tortilla production. Cereal Foods World, 33 (10):855-864.

Shalaby, A. R., Nefisa A. Hegazy, F. A. Salem, Somaya M. Abd El-Moneim and A. M. Hussein (2004). Production of tortilla chips from corn and/or sorghum. II. Evaluation of starch gelatinization. J. Agric. Sci. Mansoura Univ., 29 (12) 7111- 7130.

Shalaby, A. R., Nefisa A. Hegazy, F. A. Salem, Somaya M. Abd El-Moneim and A. M. Hussein (2008). Production of tortilla chips from corn and/or sorghum. IV. Storage Stability with regard to packing materials. J Egypt. J. Nutr. XXIII: 49 - 67.

Stollman, U.;F. Johansson and A.Leufuen (1992). Packaging and food quality. Chap. 4.P.52-71, in "Shelf life Evaluation of Food ". Edit by C.M. Man and A.A. Jones published by Blackic Academic and Professional, an imprint of Chapman \& Hall, Wester Cleddens Road, Bishopbriggs, Glasgow. 
إنتاج شيبسى الطرطية من الذرة / السورجم:

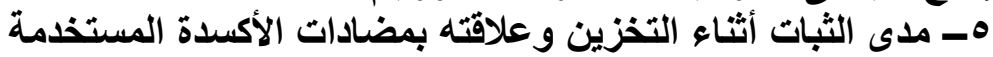

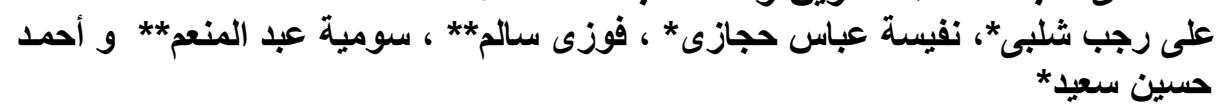

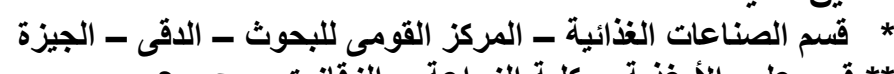

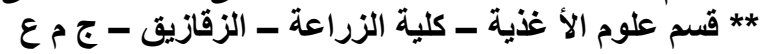

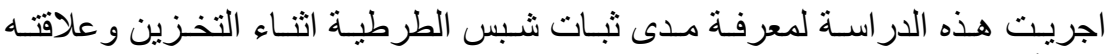

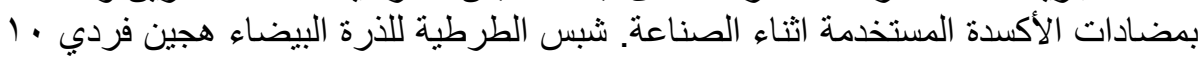

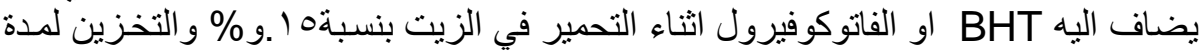

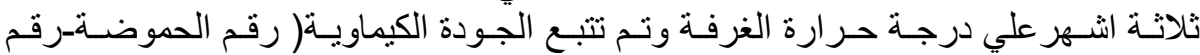

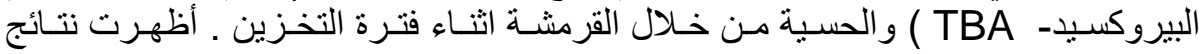

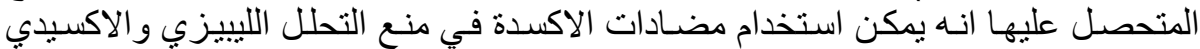

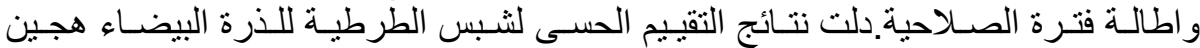

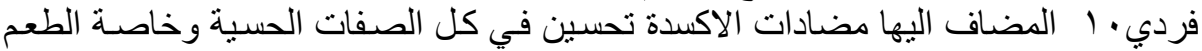

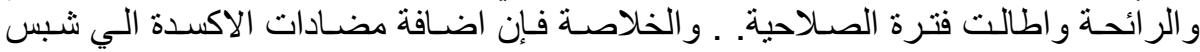

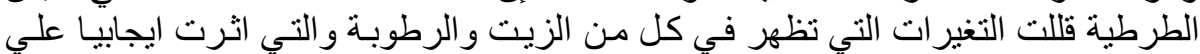
قرمشة شبس الطرطية المخزنة.

كلية الزراعة - جامعة المنصورة

قام بتحكيم البحث كلية الزراعة - جامعة القاهرة

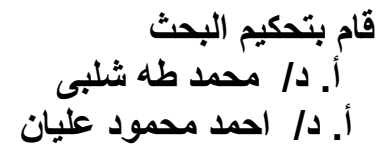

